\title{
Development of a patient-reported outcome measure for the assessment of symptom burden in pediatric chronic kidney disease (PRO-Kid)
}

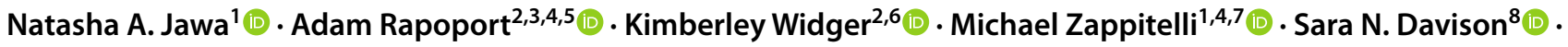 \\ Sarita $\mathrm{Jha}^{9} \cdot$ Allison B. Dart ${ }^{9,10} \cdot$ Mina Matsuda-Abedini $^{1,4}$
}

Received: 21 June 2021 / Revised: 6 August 2021 / Accepted: 6 August 2021 / Published online: 10 November 2021

(c) The Author(s), under exclusive licence to International Pediatric Nephrology Association 2021

\begin{abstract}
Background Chronic kidney disease (CKD) and kidney failure in childhood are associated with significant and life-altering morbidities and lower quality of life. Emerging evidence suggests that management should be guided in part by symptom burden; however, there is currently no standardized assessment tool for quantifying symptom burden in this pediatric population. This study aimed to develop and refine a patient-reported symptom assessment tool for children with CKD/kidney failure (PRO-Kid), to evaluate the frequency and impact of symptoms.

Methods This was a prospective observational study of children and caregivers of children with CKD/kidney failure at two Canadian pediatric care centers. Building on previously published patient-reported outcome measures (PROs) for the assessment of symptom burden in other populations, we drafted a 13-item questionnaire. Cognitive interviews were performed with children and caregivers of children with $\mathrm{CKD} /$ kidney failure to iteratively refine the questionnaire.

Results Twenty-four participants completed cognitive interviewing (11 children, 13 caregivers). The most common symptoms endorsed were feeling left out, feeling sad/depressed, inability to focus, tiredness, nausea, vomiting, not wanting to eat, and changes in the taste of food. Feeling left out was added to the questionnaire as almost all participants voiced this as a frequent and impactful symptom, resulting in a 14-item questionnaire.

Conclusions PRO-Kid is the first pediatric CKD/kidney failure-specific PRO tool to assess symptom burden. Future work should validate this tool in a larger cohort so that it may be used to improve the care of children living with CKD/kidney failure.
\end{abstract}

Keywords Chronic kidney disease $\cdot$ Patient-reported outcomes $\cdot$ Quality of life $\cdot$ Cognitive interview

Allison B. Dart and Mina Matsuda-Abedini contributed equally to this work.

Allison B. Dart and Mina Matsuda-Abedini are co-senior authors

Mina Matsuda-Abedini

mina.matsuda-abedini@sickkids.ca

1 Division of Nephrology, The Hospital for Sick Children, Toronto, ON, Canada

2 Paediatric Advanced Care Team, The Hospital for Sick Children, Toronto, ON, Canada

3 Emily's House Children's Hospice, Toronto, ON, Canada

4 Department of Paediatrics, Faculty of Medicine, University of Toronto, Toronto, ON, Canada

5 Department of Family \& Community Medicine, Faculty of Medicine, University of Toronto, Toronto, ON, Canada
6 Lawrence S. Bloomberg Faculty of Nursing, University of Toronto, Toronto, ON, Canada

7 Child Health Evaluative Sciences, SickKids Research Institute, Toronto, ON, Canada

8 Division of Nephrology and Immunology, University of Alberta, Edmonton, AB, Canada

9 Children's Hospital Research Institute of Manitoba, Winnipeg, MB, Canada

10 Department of Pediatrics and Child Health, University of Manitoba, Winnipeg, MB, Canada 


\section{Introduction}

The exact prevalence of childhood chronic kidney disease (CKD) and kidney failure is unknown, with an estimated prevalence of 55-60 per million age-related population [1]. Childhood-onset CKD/kidney failure is associated with lifelong and life-altering morbidities, with patients experiencing nausea, anorexia, delayed growth, fatigue, social isolation, impaired cognitive function, depression, and low self-esteem [2-4]. Children with kidney failure report significantly lower health-related quality of life compared to healthy children [5]. Identifying and addressing these morbidities is critical to improving quality of life for these children.

Healthcare providers commonly rely on quantitative laboratory, imaging, or histopathological measures of kidney health to assess disease progression and determine treatment options. However, trial data in adults suggests that important decisions, such as timing of dialysis initiation, should be guided by symptom severity rather than laboratory testing (e.g., estimated glomerular filtration rate (eGFR)) alone [6, 7].

Symptom burden has been identified as a top research priority by patient partners of the Canadians Seeking Solutions and Innovations to Overcome CKD (Can-SOLVE CKD) Strategic Patient Oriented Research (SPOR) network, aimed to improve care for patients living with CKD [8]. Discussions among patient partners, healthcare providers, and policy-makers led to priority themes for kidney research, where decreasing symptoms of advanced CKD was endorsed as a top priority by both adult and pediatric nephrology groups.

Symptoms of CKD/kidney failure are highly variable, with children experiencing a range of symptoms and severities at different times during their disease progression. Furthermore, the impact of the symptoms may vary for children with similar symptoms. Currently, there is no validated, disease-specific symptom assessment tool for children with $\mathrm{CKD} /$ kidney failure.

PROs are measurements based on direct patient reports about the status of their health and disease, without interpretation by healthcare providers or caregivers [9]. While emerging studies have shown that children with CKD want more involvement in treatment decision-making [10], a pediatric CKD-specific PRO is not currently available. A validated pediatric CKD PRO has the potential to significantly improve patient-provider communications and enable children and adolescents to become partners in their care. It may also guide clinical decision-making surrounding treatment initiation or disease management, standardize evaluation of existing and future treatments, and enable longitudinal assessment of quality of care.

The objective of this study was to identify symptoms most relevant to children with CKD and kidney failure and develop a PRO measure for assessing frequency and impact of these symptoms. We describe here the process of developing the PRO-Kid questionnaire.

\section{Materials and methods}

\section{Study design and context}

This was a cross-sectional cognitive interviewing study of children with CKD/kidney failure to develop and evaluate the patient- and caregiver-specific content and face validity of a novel symptom assessment tool: PRO-Kid questionnaire. The study was conducted at The Hospital for Sick Children (SickKids, Toronto, Ontario) and the Health Sciences Centre Children's Hospital (Winnipeg, Manitoba).

\section{Development of the PRO-Kid questionnaire}

We identified the most relevant, pre-existing, validated, and published tools for use in children with $\mathrm{CKD} /$ kidney failure. Relevant tools were the Symptom Screening in Pediatrics (SSPedi, used in pediatric oncology [11]); the Memorial Symptom Assessment Scale (MSAS, with versions validated for children with cancer age 7-12 and 10-18 years [12, 13]); the Patient-Reported Outcome Measurement Information System (PROMIS ${ }^{\circledR}$, for use across many illnesses [14]); and the Edmonton Symptom Assessment System-Revised: Renal (ESAS-r:R, for adults with kidney failure [15]). While the SSPedi is specific for use in children, and the MSAS is validated in patients 7 years and older, neither is disease-specific to CKD/kidney failure and may not capture symptoms important to children with $\mathrm{CKD} /$ kidney failure. PROMIS ${ }^{\circledR}$ also lacks the specificity required to delineate $\mathrm{CKD} /$ kidney failure-specific symptom burden, as it was not specifically designed for pediatric $\mathrm{CKD} /$ kidney failure. Furthermore, the PROMIS ${ }^{\circledR}$ is long and can be challenging to use as a bedside tool to document disease progression. Finally, the ESAS-r:R, while disease-specific, was not designed nor validated for use in children.

After careful review of the content and structure of these existing validated tools (i.e., the SSPedi, MSAS, PROMIS ${ }^{\circledR}$, and ESAS-r:R), two team members (MMA and AD) developed an initial draft of the PRO-Kid questionnaire template, drawing on items included in the existing questionnaires which, in the opinion of the investigators, were relevant to a pediatric CKD population. This initial list of items was then iteratively revised through feedback and modifications from investigator and patient team members. Thirteen symptoms, capturing emotional, cognitive, and physical elements were identified as most relevant to children with CKD/kidney failure. Given the importance of understanding the burden of symptoms, both frequency and impact (i.e., how bothersome 
the symptom is in their everyday life) were included for assessment. A 5-point scale ranging from "not at all" to "always" was created to evaluate frequency, and "not at all" to "extremely bothered" for impact. Prior literature has shown the appropriateness of such scales for PRO tools in children at least 8 years old [16]. Finally, a recall period of 7 days was selected based on existing tools and consensus (AR, KW, MZ, SD, AD, MMA) that 7 days would capture the most immediate symptoms. A 1-month recall period has been reported to be too long, while fewer than 7 days may be too short to capture pertinent symptoms [17].

\section{Proposed scoring system}

Each item on the PRO-Kid questionnaire is rated on a 5-point scale for the dimensions of frequency and impact. Scores are summed to yield a component score for each of frequency and impact. Component scores are then summed to yield a total composite score. Higher scores indicate higher symptom burden. Assessment of this proposed scoring system should be evaluated through future research.

\section{Participants}

Patients (Patient Group) were included if they were age 8-18 years, diagnosed with CKD GFR category $(\mathrm{G}) 2-5$ (eGFR $<90 \mathrm{ml} / \mathrm{min} / 1.73 \mathrm{~m}^{2}$, determined by bedside Schwartz equation [18]), or kidney failure, on peritoneal or hemodialysis. Children $>7$ were selected because they are able to complete self-report questionnaires [19]. Patients were excluded if they had an intellectual disability that affected their ability to complete the questionnaire or interview, were unable to speak or understand English, or had undergone kidney transplantation.

Parents and/or legal guardians of children with CKD/ kidney failure were included in the Caregiver Group. They did not need to be parents or legal guardians of children enrolled in the Patient Group; however, child-parent dyads were permitted. Caregivers were excluded if they had an intellectual disability that affected their ability to complete the questionnaire or interview or were unable to speak or understand English.

\section{Sampling strategy}

Purposive sampling by the investigators at each site (AD, MMA) was used to ensure that participants encompassed the range of age, sex, and CKD stage representative of this population. To achieve this, investigators identified male and female children from their practice who spanned the ages eligible for inclusion (8-18 years), from stages 2-5 CKD including dialysis. Potential participants were approached to determine their interest in study participation during their routine visit to nephrology clinic.

We did not have a specific a priori sample size; cognitive interviewing continued until information saturation was reached (i.e., no new information was being generated from interviews) [20].

\section{Data collection methods}

\section{Data elements}

Demographic information pertaining to the Patient Group was collected via self-report or caregiver report. For the Caregiver Group, demographic and clinical information was collected on the child with $\mathrm{CKD} /$ kidney failure from the caregiver participant. Demographic information included sex, age, ethnicity, primary diagnosis, grade level, location in a rural vs. urban setting, distance from home to treatment center, and highest level of education of the child's primary caregiver. Clinical information pertaining to the Patient Group was obtained from the patient's electronic medical record and included need for G-tube, intermittent bladder catheterizations, eGFR, CKD stage based on eGFR [18], and dialysis modality. All data were entered into a passwordprotected Research Electronic Data Capture (REDCap [21]) database at SickKids.

\section{Cognitive interviews}

Cognitive interviews were used to assess the content and face validity of the PRO-Kid questionnaire and to make iterative modifications. Cognitive interviewing is an established technique to evaluate PRO questionnaires, by assessing the respondent's understanding of questions or words [20]. An experienced clinical research manager (NAJ, MSc) with no prior relationship to the study participants received specialized training by Survey Research Group (SRG), a program of the Public Health Institute (Sacramento, California; https://www.phi.org/). To maintain consistency, a single interviewer conducted all interviews at both sites. Participants were informed that the facilitator was a researcher involved in the study but had no personal motivations for engaging in the research. Participants were also informed that the purpose of the interviews was to understand the symptoms experienced by patients with $\mathrm{CKD} /$ kidney failure in order to develop a tool to assess the burden of symptoms in a clinical setting. A research assistant from each site participated in the interviews as a field note recorder.

All interviews were conducted virtually using the Microsoft Teams online video communications platform. Participants were provided with a link to join the meeting, along with instructions on how to use the program. Participants without access to a computer or internet were able to 
schedule their interviews at their regular hospital appointment. Interviews of children and their caregivers were conducted separately to mitigate biasing of responses. However, caregivers were permitted to stay in the room while children were interviewed. Each participant was interviewed once during a $30-$ min session, with no repeat interviews.

Interviews began with open-ended questions, to probe how living with CKD affects the child. Participants were also asked to comment on the symptoms that would be most relevant to include in a symptom assessment questionnaire, based on their own experience. Children and caregivers were then asked to electronically complete the PRO-Kid questionnaire, using the survey function through REDCap. The interviewer guided participants if needed as they completed the questionnaire, including providing a pre-defined set of synonyms to clarify the meaning of any words that the participant did not understand (e.g., "bug" to describe symptoms that were "bothersome") or reading questions aloud to participants verbatim.

After completing the questionnaire, participants completed another short interview, where the interviewer assessed the ease of completion of the questionnaire, evaluated understandability of each item using cognitive probing, and assessed the face and content validity of each item on the questionnaire. Participants were also asked to comment on their understanding of the rating scales and timeline (i.e., "in the past week") used in the questionnaire. Participants were asked about each item's importance and whether the symptom bothers them enough to ask about it regularly. Finally, participants were asked whether any symptoms were missing from the questionnaire that they felt should be included and whether there were any items that they felt could be removed from the questionnaire.

All interviews were audio recorded. Following each interview, information from the audio recordings was used to augment and amend the field notes for accuracy and completeness. Transcripts of the interviews were not provided to participants for comment and/or correction.

\section{Data processing and analysis}

Data was coded and thematic content analysis conducted (NAJ) using NVivo (https://qsinternational.com/nvivo). The study team (NAJ, AD, MMA, AR, SD, KW, MZ) reviewed responses from the interviews on an ongoing basis as participants completed the study, to determine whether the questionnaire warranted modification. Results were reviewed after the first 10 participants and again after 15 and 24 participants had been interviewed. Standards for decision-making regarding questionnaire item modification were determined a priori via consensus from the study team. Items were assessed as requiring modification if at least $30 \%$ of participants found an item "hard" or "very hard" to understand or at least $30 \%$ had interviewer ratings of "incorrect" for their understandability. Any symptoms identified as not bothersome enough to ask about regularly by at least $70 \%$ were removed. Any new symptoms endorsed by at least $70 \%$ were added to subsequent versions of the questionnaire in order to obtain other participants' perspectives on whether or not the item was relevant and important. Participants did not provide feedback on the findings; however, parent partners reviewed and provided feedback on the overall study results.

\section{Statistical analysis}

Patient and caregiver characteristics were summarized as mean and standard deviation (SD) for continuous variables, or frequencies and percentages for categorical variables. Symptom clusters were identified as symptoms that patients often endorsed together. A hierarchical analysis was performed to understand the symptoms most frequently endorsed in each of three domains: physical, emotional, and cognitive. These domains were selected a priori by the research team (AR, KW, SD, MZ, AD, MMA) to ensure that the final questionnaire would cover the full range of symptoms experienced by patients. This analysis was conducted prior to participants viewing the PRO-Kid questionnaire and was based solely on the open-ended portion of each interview.

\section{Results}

\section{Sample characteristics}

A total of 11 children and 13 caregivers were enrolled. Nine child-caregiver dyads were from the same family. Four individual parents and two individual children also participated. Demographic data on all participating children is summarized in Table 1.

PRO-Kid questionnaire data was missing for one child, who did not save their questionnaire results prior to exiting the survey; however, interview data was still obtained. On average, participants took 5 min to complete the questionnaire and did not require any assistance from the interviewer (Fig. 1).

\section{Cluster identification from cognitive interviews}

Prior to participants viewing the questionnaire, openended feedback from the cognitive interviews demonstrated symptoms endorsed in the three domains established a priori: emotional, physical, and cognitive. Emotional symptoms included sadness/depression, 
Table 1 Demographic data for children with CKD/kidney failure

\begin{tabular}{|c|c|c|}
\hline Demographic & Descriptor & Value \\
\hline \multirow[t]{2}{*}{$\operatorname{Sex}(n, \%)$} & Female & $6(54.5)$ \\
\hline & Male & $5(45.5)$ \\
\hline Age (mean, SD) & & $13(3.6)$ \\
\hline \multirow[t]{2}{*}{ Ethnicity $(n, \%)$} & Caucasian/European & $7(63.6)$ \\
\hline & Other & $4(36.4)$ \\
\hline \multirow[t]{4}{*}{ Primary diagnosis $(n, \%)$} & CAKUT & $6(54.5)$ \\
\hline & Autoimmune & $2(18.2)$ \\
\hline & FSGS & $2(18.2)$ \\
\hline & Unknown & $1(9.1)$ \\
\hline \multirow[t]{3}{*}{ Grade level $(n, \%)$} & Above grade level & $2(18.2)$ \\
\hline & At grade level & $5(45.5)$ \\
\hline & Below grade level & $4(36.3)$ \\
\hline \multirow[t]{2}{*}{ Location $(n, \%)$} & Urban & $7(63.7)$ \\
\hline & Rural & $4(36.3)$ \\
\hline \multirow[t]{3}{*}{ Distance from treatment center $(n, \%)$} & $<50 \mathrm{~km}$ & $8(72.7)$ \\
\hline & $50-150 \mathrm{~km}$ & $2(18.2)$ \\
\hline & $150-300 \mathrm{~km}$ & $1(9.1)$ \\
\hline \multirow[t]{5}{*}{ Highest level of education of mother $(n, \%)$} & Graduate university & $2(18.2)$ \\
\hline & Professional degree & $1(9.1)$ \\
\hline & College & $2(18.2)$ \\
\hline & Secondary school & $2(18.2)$ \\
\hline & Unknown & $3(27.3)$ \\
\hline \multirow[t]{5}{*}{ Highest level of education of father $(n, \%)$} & Graduate university & $2(18.2)$ \\
\hline & Professional degree & $1(9.1)$ \\
\hline & College & $2(18.2)$ \\
\hline & Secondary school & $2(18.2)$ \\
\hline & Unknown & $4(36.3)$ \\
\hline G-tube fed $(n, \%)$ & & $0(0.0)$ \\
\hline Intermittent catheterizations $(n, \%)$ & & $1(9.1)$ \\
\hline eGFR, all participants (mean, SD) & & $28.3(21.5)$ \\
\hline \multirow[t]{5}{*}{ CKD stage, not on dialysis $(n, \%)$} & 2 & $1(14.2)$ \\
\hline & $3 a$ & $1(14.2)$ \\
\hline & $3 b$ & $2(28.6)$ \\
\hline & 4 & $3(43.0)$ \\
\hline & 5 & $0(0.0)$ \\
\hline CKD stage 5 (on dialysis) $(n, \%)$ & & $4(36.3)$ \\
\hline \multirow[t]{2}{*}{ Modality $(n, \%)$} & HD & $1(9.1)$ \\
\hline & PD & $3(27.3)$ \\
\hline
\end{tabular}

$S D$ standard deviation; CAKUT congenital anomalies of the kidney and urinary tract; FSGS focal segmental glomerulosclerosis; $e G F R$ estimated glomerular filtration rate; $C K D$ chronic kidney disease; $H D$ hemodialysis; $P D$ peritoneal dialysis anxiety, frustration, and feeling left out. Physical symptoms included concerns over physical size (i.e., short stature), swelling, temperature, shortness of breath, weakness, headache, nausea/vomiting, constipation, itching, kidney pain, stomach ache, not wanting to eat, and changes in taste of food. Problems with sleep were also described by participants in terms of tiredness/exhaustion, waking up to urinate, feeling tired, or feeling restless. Cognitive symptoms included lack of ability to focus and issues with school. Frequency of symptom endorsement at the first interim assessment (after 10 participants had been interviewed) is described in Table 2.

A variety of symptom clusters were revealed (Fig. 2). For example, we noticed that participants who endorsed feeling tired as a frequent and/or burdensome symptom were also likely to report waking up to urinate and feeling restless 
Fig. 1 Final PRO-Kid questionnaire
PRO-Kid Questionnaire

田।日
Participant ID:

Date:

12 Today

Please tell us how often you had each of these feelings AND how much they bothered you in the past week by clicking the bubble that best describes the amount. Please rate the following items for frequency and impact:

\begin{tabular}{|c|c|c|c|c|c|c|c|c|c|c|}
\hline \multirow[b]{2}{*}{ Feeling sad } & \multicolumn{5}{|c|}{$\begin{array}{c}\text { FREQUENCY } \\
\text { In the past week, how } \\
\text { often did you have this } \\
\text { symptom? }\end{array}$} & \multicolumn{5}{|c|}{ IMPACT } \\
\hline & $\begin{array}{l}\text { Not at } \\
\text { all } \\
0\end{array}$ & $\begin{array}{c}\text { A little } \\
\bigcirc\end{array}$ & $\begin{array}{c}\text { Medium } \\
\bigcirc\end{array}$ & $\begin{array}{c}\text { A lot } \\
0\end{array}$ & $\begin{array}{c}\text { Alwoys } \\
0\end{array}$ & $\begin{array}{l}\text { Not at } \\
\text { all } \\
0\end{array}$ & $\begin{array}{c}\text { A little } \\
\bigcirc\end{array}$ & $\begin{array}{c}\text { Medium } \\
\bigcirc\end{array}$ & $\begin{array}{c}\text { A lot } \\
0\end{array}$ & $\begin{array}{c}\text { Extremely } \\
\text { bothered } \\
0\end{array}$ \\
\hline Feeling scared or worried & $\begin{array}{l}\text { Not at } \\
\text { all } \\
0\end{array}$ & $\begin{array}{c}\text { A little } \\
\bigcirc\end{array}$ & $\begin{array}{c}\text { Medium } \\
\bigcirc\end{array}$ & $\begin{array}{c}\text { A lot } \\
0\end{array}$ & $\begin{array}{c}\text { Alwoys } \\
\bigcirc\end{array}$ & $\begin{array}{l}\text { Not at } \\
\text { all } \\
0\end{array}$ & $\begin{array}{c}\text { A little } \\
\bigcirc\end{array}$ & $\begin{array}{c}\text { Medium } \\
\bigcirc\end{array}$ & $\begin{array}{c}\text { A lot } \\
0\end{array}$ & $\begin{array}{c}\text { Extremely } \\
\text { bothered } \\
\bigcirc\end{array}$ \\
\hline Feeling left out & $\begin{array}{l}\text { Not at } \\
\text { all } \\
0\end{array}$ & $\begin{array}{c}\text { A little } \\
\bigcirc\end{array}$ & $\begin{array}{c}\text { Medium } \\
\bigcirc\end{array}$ & $\begin{array}{c}\text { A lot } \\
0\end{array}$ & $\begin{array}{c}\text { Alwoys } \\
0\end{array}$ & $\begin{array}{l}\text { Not at } \\
\text { all } \\
0\end{array}$ & $\begin{array}{c}\text { A little } \\
\bigcirc\end{array}$ & $\begin{array}{c}\text { Medium } \\
\bigcirc\end{array}$ & $\begin{array}{c}\text { A lot } \\
0\end{array}$ & $\begin{array}{c}\text { Extremely } \\
\text { bothered } \\
0\end{array}$ \\
\hline Feeling tired & $\begin{array}{c}\text { Not at } \\
\text { all } \\
0\end{array}$ & $\begin{array}{c}\text { A little } \\
\bigcirc\end{array}$ & $\begin{array}{c}\text { Medium } \\
\bigcirc\end{array}$ & $\begin{array}{c}\text { A lot } \\
0\end{array}$ & $\begin{array}{c}\text { Alwoys } \\
\bigcirc\end{array}$ & $\begin{array}{l}\text { Not at } \\
\text { all } \\
0\end{array}$ & $\begin{array}{c}\text { A little } \\
\bigcirc\end{array}$ & $\begin{array}{c}\text { Medium } \\
\bigcirc\end{array}$ & $\begin{array}{c}\text { A lot } \\
0\end{array}$ & $\begin{array}{c}\text { Extremely } \\
\text { bothered } \\
0\end{array}$ \\
\hline $\begin{array}{l}\text { Feeling like you may throw } \\
\text { up or throwing up }\end{array}$ & $\begin{array}{c}\text { Not at } \\
\text { all } \\
0\end{array}$ & $\begin{array}{c}\text { A little } \\
\bigcirc\end{array}$ & $\begin{array}{c}\text { Medium } \\
\bigcirc\end{array}$ & $\begin{array}{c}\text { A lot } \\
0\end{array}$ & $\begin{array}{c}\text { Alwoys } \\
0\end{array}$ & $\begin{array}{l}\text { Not at } \\
\text { all } \\
0\end{array}$ & $\begin{array}{c}\text { A little } \\
\bigcirc\end{array}$ & $\begin{array}{c}\text { Medium } \\
\bigcirc\end{array}$ & $\begin{array}{c}\text { A lot } \\
0\end{array}$ & $\begin{array}{c}\text { Extremely } \\
\text { bothered } \\
0\end{array}$ \\
\hline Don't feel like eating & $\begin{array}{l}\text { Not at } \\
\text { all } \\
\mathrm{O}\end{array}$ & $\begin{array}{c}\text { A little } \\
\bigcirc\end{array}$ & $\begin{array}{c}\text { Medium } \\
\bigcirc\end{array}$ & $\begin{array}{c}\text { A lot } \\
\bigcirc\end{array}$ & Alwoys & $\begin{array}{l}\text { Not at } \\
\text { all } \\
0\end{array}$ & $\begin{array}{c}\text { A little } \\
\bigcirc\end{array}$ & $\begin{array}{c}\text { Medium } \\
\bigcirc\end{array}$ & $\begin{array}{c}\text { A lot } \\
0\end{array}$ & $\begin{array}{c}\text { Extremely } \\
\text { bothered } \\
0\end{array}$ \\
\hline Can't sleep well & $\begin{array}{l}\text { Not ot } \\
\text { all } \\
0\end{array}$ & $\begin{array}{c}\text { A little } \\
\bigcirc\end{array}$ & $\begin{array}{c}\text { Medium } \\
\bigcirc\end{array}$ & $\begin{array}{c}\text { A lot } \\
0\end{array}$ & $\begin{array}{c}\text { Alwoys } \\
0\end{array}$ & $\begin{array}{l}\text { Not at } \\
\text { all } \\
0\end{array}$ & $\begin{array}{c}\text { A little } \\
\bigcirc\end{array}$ & $\begin{array}{c}\text { Medium } \\
\bigcirc\end{array}$ & $\begin{array}{c}\text { A lot } \\
0\end{array}$ & $\begin{array}{c}\text { Extremely } \\
\text { bothered } \\
0\end{array}$ \\
\hline $\begin{array}{l}\text { Problems with thinking or } \\
\text { concentrating (not able to } \\
\text { focus) }\end{array}$ & $\begin{array}{l}\text { Not ot } \\
\text { all } \\
0\end{array}$ & $\begin{array}{c}\text { A little } \\
\mathrm{O}\end{array}$ & $\begin{array}{l}\text { Medium } \\
\bigcirc\end{array}$ & $\begin{array}{c}\text { A lot } \\
\bigcirc\end{array}$ & $\begin{array}{c}\text { Alwoys } \\
0\end{array}$ & $\begin{array}{l}\text { Not ot } \\
\text { all } \\
0\end{array}$ & A little & Medium & $\begin{array}{c}\text { A lot } \\
0\end{array}$ & $\begin{array}{c}\text { Extremely } \\
\text { bothered } \\
0\end{array}$ \\
\hline $\begin{array}{l}\text { Constipation (hard to } \\
\text { poop) }\end{array}$ & $\begin{array}{c}\text { Not at } \\
\text { all } \\
0\end{array}$ & $\begin{array}{c}\text { A little } \\
\bigcirc\end{array}$ & $\begin{array}{c}\text { Medium } \\
\bigcirc\end{array}$ & $\begin{array}{c}\text { A lot } \\
0\end{array}$ & $\begin{array}{c}\text { Alwoys } \\
0\end{array}$ & $\begin{array}{c}\text { Not at } \\
\text { all } \\
0\end{array}$ & $\begin{array}{c}\text { A little } \\
\bigcirc\end{array}$ & $\begin{array}{c}\text { Medium } \\
\bigcirc\end{array}$ & $\begin{array}{c}\text { A lot } \\
0\end{array}$ & $\begin{array}{c}\text { Extremely } \\
\text { bothered } \\
0\end{array}$ \\
\hline Itching & $\begin{array}{c}\text { Not at } \\
\text { all } \\
0\end{array}$ & $\begin{array}{c}\text { A little } \\
\bigcirc\end{array}$ & $\begin{array}{c}\text { Medium } \\
\bigcirc\end{array}$ & $\begin{array}{c}\text { A lot } \\
0\end{array}$ & $\begin{array}{c}\text { Alwoys } \\
0\end{array}$ & $\begin{array}{c}\text { Not at } \\
\text { all } \\
0\end{array}$ & $\begin{array}{c}\text { A little } \\
\bigcirc\end{array}$ & $\begin{array}{c}\text { Medium } \\
\bigcirc\end{array}$ & $\begin{array}{c}\text { A lot } \\
0\end{array}$ & $\begin{array}{c}\text { Extremely } \\
\text { bothered } \\
0\end{array}$ \\
\hline Headache & $\begin{array}{c}\text { Not at } \\
\text { all } \\
\mathrm{O}\end{array}$ & $\begin{array}{c}\text { A little } \\
\bigcirc\end{array}$ & $\begin{array}{c}\text { Medium } \\
\bigcirc\end{array}$ & $\begin{array}{c}\text { A lot } \\
0\end{array}$ & $\begin{array}{c}\text { Alwoys } \\
0\end{array}$ & $\begin{array}{c}\text { Not at } \\
\text { all } \\
0\end{array}$ & $\begin{array}{c}\text { A little } \\
\bigcirc\end{array}$ & $\begin{array}{c}\text { Medium } \\
\bigcirc\end{array}$ & $\begin{array}{c}\text { A lot } \\
0\end{array}$ & $\begin{array}{c}\text { Extremely } \\
\text { bothered } \\
0\end{array}$ \\
\hline Pain (other than headache) & $\begin{array}{c}\text { Not } a t \\
\text { all } \\
0\end{array}$ & $\begin{array}{c}\text { A little } \\
\bigcirc\end{array}$ & $\begin{array}{c}\text { Medium } \\
\bigcirc\end{array}$ & $\begin{array}{c}\text { A lot } \\
0\end{array}$ & $\begin{array}{c}\text { Alwoys } \\
0\end{array}$ & $\begin{array}{c}\text { Not at } \\
\text { all } \\
0\end{array}$ & $\begin{array}{c}\text { A little } \\
\bigcirc\end{array}$ & $\begin{array}{c}\text { Medium } \\
\bigcirc\end{array}$ & $\begin{array}{c}\text { A lot } \\
0\end{array}$ & $\begin{array}{c}\text { Extremely } \\
\text { bothered } \\
0\end{array}$ \\
\hline Trouble breathing & $\begin{array}{c}\text { Not at } \\
\text { all } \\
0\end{array}$ & $\begin{array}{c}\text { A little } \\
\bigcirc\end{array}$ & $\begin{array}{c}\text { Medium } \\
\bigcirc\end{array}$ & $\begin{array}{c}\text { A lot } \\
\bigcirc\end{array}$ & $\begin{array}{c}\text { Alwoys } \\
0\end{array}$ & $\begin{array}{c}\text { Not at } \\
\text { all } \\
0\end{array}$ & $\begin{array}{c}\text { A little } \\
\bigcirc\end{array}$ & $\begin{array}{c}\text { Medium } \\
\bigcirc\end{array}$ & $\begin{array}{c}\text { A lot } \\
0\end{array}$ & $\begin{array}{c}\text { Extremely } \\
\text { bothered } \\
0\end{array}$ \\
\hline Changes in taste of food & $\begin{array}{c}\text { Not at } \\
\text { all } \\
0\end{array}$ & $\begin{array}{c}\text { A little } \\
\bigcirc\end{array}$ & $\begin{array}{c}\text { Medium } \\
\bigcirc\end{array}$ & $\begin{array}{c}\text { A lot } \\
\bigcirc\end{array}$ & $\begin{array}{c}\text { Alwoys } \\
0\end{array}$ & $\begin{array}{c}\text { Not at } \\
\text { all } \\
0\end{array}$ & $\begin{array}{c}\text { A little } \\
\bigcirc\end{array}$ & $\begin{array}{c}\text { Medium } \\
\bigcirc\end{array}$ & $\begin{array}{c}\text { A lot } \\
0\end{array}$ & $\begin{array}{c}\text { Extremely } \\
\text { bothered } \\
0\end{array}$ \\
\hline
\end{tabular}

during the daytime. Similarly, feelings of sadness, anxiety, and frustration were often clustered together.

\section{Hierarchical analysis}

Results of the hierarchical analysis are outlined in Fig. 3. The most common emotional symptoms were feeling left out 
Table 2 Symptom endorsement by the first 10 patients and caregivers

\begin{tabular}{lll}
\hline Symptom & $\begin{array}{l}\text { Number of par- } \\
\text { ticipants }(N=10)\end{array}$ & $\begin{array}{l}\text { Number of times } \\
\text { referenced across all } \\
\text { interviews }\end{array}$ \\
\hline Tiredness & 8 & 16 \\
Feeling left out & 8 & 15 \\
Frustration & 7 & 8 \\
Pain & 5 & 5 \\
Nausea & 4 & 5 \\
Vomiting & 3 & 3 \\
Depression & 2 & 4 \\
Lack of focus & 2 & 4 \\
Not wanting to eat & 2 & 4 \\
Change in taste of food & 2 & 3 \\
Temperature & 2 & 3 \\
Anxiety & 2 & 2 \\
Itching & 2 & 2 \\
Restlessness & 2 & 2 \\
Difficulties in school & 2 & 2 \\
Swelling & 2 & 2 \\
Constipation & 1 & 1 \\
Headache & 1 & 1 \\
Shortness of breath & 1 & 1 \\
Waking up to urinate & 1 & 1 \\
Weakness & 1 & \\
\hline & & 1 \\
\hline
\end{tabular}
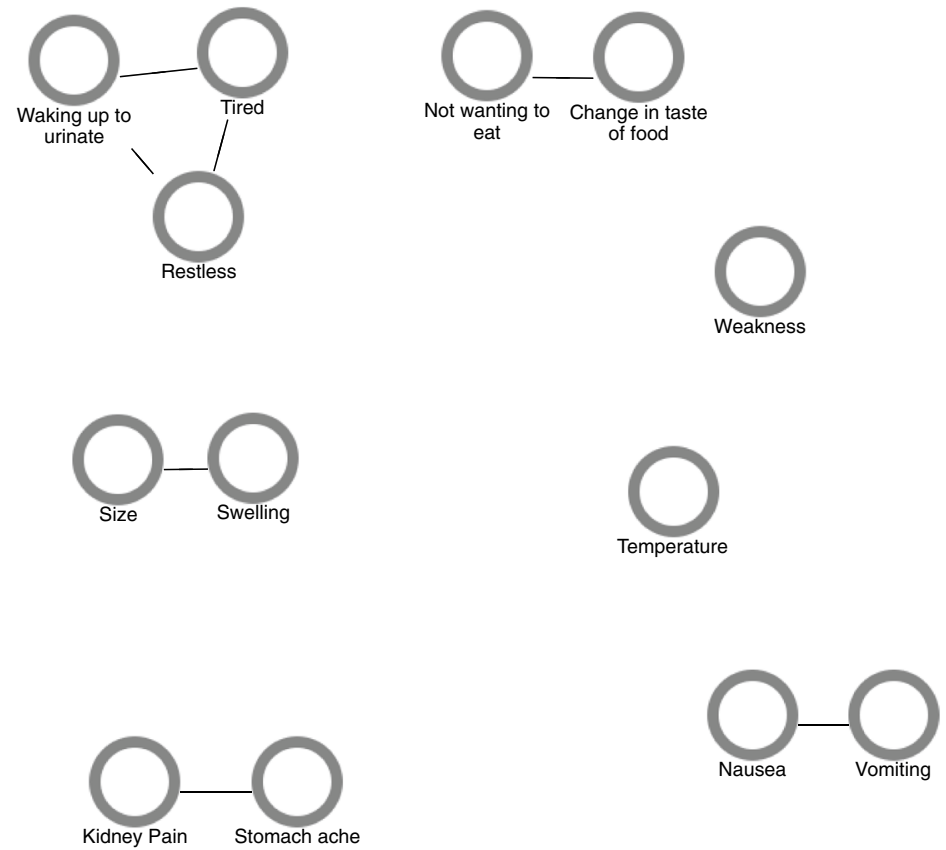

and sadness/depression. The most common cognitive symptom identified was a lack of focus. The most common physical symptoms elucidated were tiredness/exhaustion, nausea, not wanting to eat, vomiting, and changes in taste of food.

\section{Addition of questionnaire items}

Feeling left out was not initially included in our draft PROKid questionnaire but was consistently endorsed by the majority of participants during the open-ended feedback portion of the interviews, at the time of the first interim analysis ( $8 / 10$ participants). Therefore, this item was added to the subsequent iterations of the questionnaire, after the first 10 interviews were completed and analyzed.

After participants had viewed the questionnaire, specific questions were asked regarding the items, wording, and format. Problems with thinking or concentrating was the only item that consistently required clarification by the interviewer to help participants understand what was meant. Accordingly, the qualifier of "not able to focus" was added to subsequent iterations of the questionnaire. Once this qualifier was added, no further questions were asked by participants.

None of the items included on the questionnaire were endorsed as being unnecessary or irrelevant by any participant. Therefore, none of the items were removed. No participants expressed issues with the terms used to describe each item, the scale used, or the recall period. The final questionnaire is shown in Fig. 1.
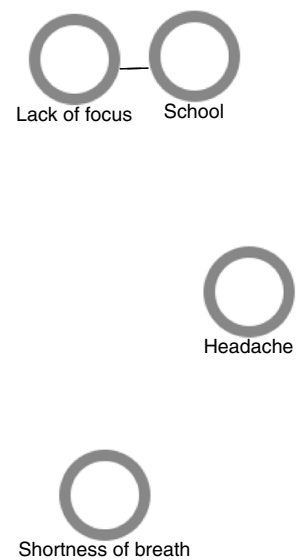
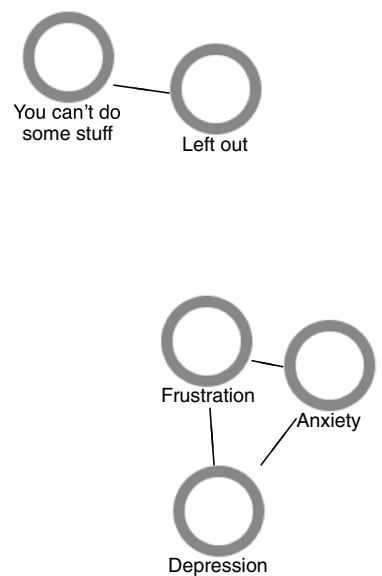

Fig. 2 Concept map of symptom clusters arising from cognitive interviews 
Fig. 3 Hierarchical map of themes arising from cognitive interviews. Size of each component box represents the relative frequency with which each symptom was described during the cognitive interviews

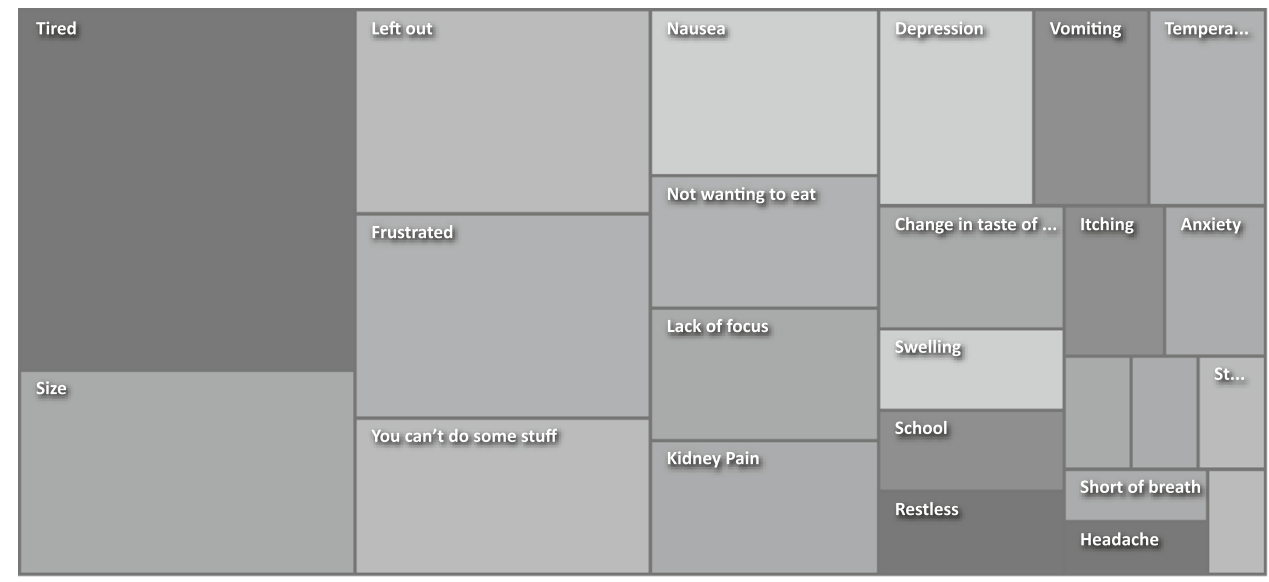

\section{Discussion}

PRO measures are increasingly recognized as an essential component of quality care delivery for patients with chronic disease. While symptoms can be subjective, PRO instruments quantitatively measure patient perspectives of health and disease, which can be incorporated into both clinical care and research [9]. This study represents a first step toward bridging this critical patient-centered healthcare gap, through the development of a PRO tool specifically for children and adolescents with CKD/kidney failure that can be used with ease in the clinical setting.

Important clinical decisions such as timing of initiation of kidney replacement therapy are guided by the presence and severity of uremic symptoms [22]. Randomized trials in adults show no benefit to early dialysis initiation based on estimated kidney function, and that symptoms should guide this decision [7, 23]. A recent cross-sectional survey of Canadian Pediatric Nephrologists by our research group showed significant practice variation regarding timing of dialysis initiation [22], a reflection of the subjectivity of symptoms in the clinical setting and lack of objective symptom assessment tools for this population. In other clinical areas, including oncology, evidence-based guidelines have been developed to manage symptoms identified by PROs [24]. There exists no such validated, disease-specific symptom assessment tool for children with CKD/kidney failure.

Our final 14-item questionnaire represents the spectrum of physical, cognitive, and emotional symptoms endorsed most frequently by our pediatric CKD/kidney failure study cohort, covering the full range of symptoms that fall within the different domains of illness. The use of open-ended cognitive interviewing techniques in conjunction with specific feedback on each iteration of the PRO-Kid questionnaire lend credence to the fact that all items thought to be important by patients and caregivers were included in the final version of the questionnaire. This methodology also supports the notion that there were no extraneous items included that were unnecessary to describe the symptom burden experienced by these children.

Participants were able to complete the final version of the questionnaire with ease, in $5 \mathrm{~min}$ or less, and without assistance from the interviewer or study staff, further supporting the feasibility of administration of this questionnaire clinically. For a tool designed for use in a busy clinical setting with multiple competing priorities, the simplicity with which the PRO-Kid questionnaire can be administered and completed is of critical importance.

A variety of PROs are available for use in other clinical contexts; however, none of the existing PROs were specifically developed for use in the pediatric CKD and kidney failure population. The present study garnered elements from pediatric-specific oncology tools [11-13], including the type of symptoms most relevant to children with chronic illness, age-appropriate language, and scales used to assess severity and impact of disease, and period of symptom recall.

Prior to study initiation, our group felt that some items on the ESAS-r:R [15] — a validated PRO that reliably assesses symptom changes longitudinally in adult hemodialysis patients [25] — may be irrelevant to children. However, there were no items deemed to be irrelevant by our participants. In spite of this, the language used in the ESAS-r:R may be difficult for some children to understand, and the 10-point scale is also potentially problematic for young children.

Furthermore, few of the existing measures assessed a range of symptom attributes (i.e., frequency and impact) [26]. A valid, symptom-focused instrument with a short recall period and assessment of multiple symptom attributes is therefore critical to improve symptom assessment among patients with kidney failure [26].

Recent literature has pointed to the importance of assessing life participation in children with CKD [27]. Life participation is a term meant to capture the full range of daily activities in which an individual may be engaged [28]. In our study, children and caregivers consistently endorsed feeling left out as a critical symptom to include in the PRO-Kid 
tool. The inclusion of this item in our tool fills a previously unmet need among all other published tools for use in this population [27].

As a result of the COVID-19 pandemic, our study was pivoted to an entirely virtual platform. This included the transition from a paper-based questionnaire to an electronic questionnaire delivered through REDCap. Consequently, a limitation of this study is that the PRO-Kid tool was assessed solely through this electronic platform and was not assessed using a paper form. This may ultimately prove to be more convenient in a clinical setting, capturing scores in electronic medical records. Furthermore, all interactions with the interviewer occurred through videoconferencing rather than inperson, which may have hindered the ability of the research team to pick up on subtle non-verbal cues from participants about their symptom burden.

\section{Conclusion}

Future research should seek to validate the PRO-Kid questionnaire in a larger cohort of pediatric patients with CKD and kidney failure. The PRO-Kid questionnaire should serve as a novel clinical and research tool and has the potential to significantly improve clinical care for children living with CKD.

Supplementary Information The online version contains supplementary material available at https://doi.org/10.1007/s00467-021-05269-4.

Acknowledgements We would like to acknowledge and thank Vedran Cockovski and Sylvia Froese for taking observational field notes during the cognitive interviews at The Hospital for Sick Children and the Children's Hospital Research Institute of Manitoba, respectively. We would also like to acknowledge and thank the three parents of children with CKD, who were critical partners in the conduct of this project: Catharine Dunn, Olga Sousa, and Ashley Audrain.

Author contribution NA Jawa, AB Dart, and M Matsuda-Abedini developed the study protocol. AB Dart and M Matsuda-Abedini obtained funding for the study, facilitated participant recruitment, participated in data analysis, and reviewed the manuscript. NA Jawa enrolled participants at SickKids, conducted all cognitive interviews, and prepared the manuscript. S Jha enrolled participants at CHRIM. A Rapoport, K Widger, M Zappitelli, and SN Davison participated in the development of study protocol and interim analyses and reviewed the manuscript for scientific content.

Funding This project was supported by an Operating Grant from the Children's Hospital Research Institute of Manitoba (OG2019-10).

Data availability The data underlying this article will be shared on reasonable request to the corresponding author.

\section{Declarations}

Ethics approval This study was approved by the SickKids Research Ethics Board (Toronto, ON, REB\#1000071303) and the University of Manitoba Health Research Ethics Board (Winnipeg, MB,
REB\#HS23303 H2019:402) and was conducted in accordance with the Declaration of Helsinki of 1975, as revised in 2013.

Consent to participate Informed consent (and assent, as appropriate) was obtained for all study participants prior to initiating study activities.

Conflict of interest The authors declare no competing interests.

\section{References}

1. Becherucci F, Roperto RM, Materassi M, Romagnani P (2016) Chronic kidney disease in children. Clin Kidney J 9:583-591

2. Tjaden L, Tong A, Henning P, Groothoff J, Craig JC (2012) Children's experiences of dialysis: a systematic review of qualitative studies. Arch Dis Child 97:395-402

3. Tong A, Wong G, McTaggart S, Henning P, Mackie F, Carroll RP, Howard K, Craig JC (2013) Quality of life of young adults and adolescents with chronic kidney disease. J Pediatr 163:1179-1185. e5

4. Roumelioti ME, Wentz A, Schneider MF, Gerson AC, Hooper S, Benfield M, Warady BA, Furth SL, Unruh ML (2010) Sleep and fatigue symptoms in children and adolescents with CKD: a cross-sectional analysis from the chronic kidney disease in children (CKiD) study. Am J Kidney Dis 55:269-280

5. Goldstein SL, Graham N, Burwinkle T, Warady B, Farrah R, Varni JW (2006) Health-related quality of life in pediatric patients with ESRD. Pediatr Nephrol 21:846-850

6. Preka E, Rees L (2020) Should we abandon GFR in the decision to initiate chronic dialysis? Pediatr Nephrol 35:1593-1600

7. Cooper BA, Branley P, Bulfone L, Collins JF, Craig JC, Fraenkel MB, Harris A, Johnson DW, Kesselhut J, Li JJ, Luxton G, Pilmore A, Tiller DJ, Harris DC, Pollock CA, IDEAL Study (2010) A randomized, controlled trial of early versus late initiation of dialysis. N Engl J Med 363:609-619

8. Levin A, Adams E, Barrett BJ, Beanlands H, Burns KD, Chiu HH, Chong K, Dart A, Ferera J, Fernandez N, Fowler E, Garg AX, Gilbert R, Harris H, Harvey R, Hemmelgarn B, James M, Johnson J, Kappel J, Komenda P, McCormick M, McIntyre C, Mahmud F, Pei Y, Pollock G, Reich H, Rosenblum ND, Scholey J, Sochett E, Tang M, Tangri N, Tonelli M, Turner C, Walsh M, Woods C, Manns B (2018) Canadians Seeking Solutions and Innovations to Overcome Chronic Kidney Disease (Can-SOLVE CKD): form and function. Can J Kidney Health Dis 5:2054358117749530

9. Selewski DT, Thompson A, Kovacs S, Papadopoulos EJ, Carlozzi NE, Trachtman H, Troost JP, Merkel PA, Gipson DS (2017) Patient-reported outcomes in glomerular disease. Clin J Am Soc Nephrol 12:140-148

10. Gutman T, Hanson CS, Bernays S, Craig JC, Sinha A, Dart A, Eddy AA, Gipson DS, Bockenhauer D, Yap HK, Groothoff J, Zappitelli M, Webb NJA, Alexander SI, Goldstein SL, Furth S, Samuel S, Blydt-Hansen T, Dionne J, Michael M, Wenderfer SE, Winkelmayer WC, Currier H, McTaggart S, Walker A, Ralph AF, Ju A, James LJ, Carter S, Tong A (2018) Child and parental perspectives on communication and decision making in pediatric CKD: a focus group study. Am J Kidney Dis 72:547-559

11. Tomlinson D, Dupuis LL, Gibson P, Johnston DL, Portwine C, Baggott C, Zupanec S, Watson J, Spiegler B, Kuczynski S, Macartney G, Sung L (2014) Initial development of the Symptom Screening in Pediatrics Tool (SSPedi). Support Care Cancer 22:71-75

12. Collins JJ, Byrnes ME, Dunkel IJ, Lapin J, Nadel T, Thaler HT, Polyak T, Rapkin B, Portenoy RK (2000) The measurement of 
symptoms in children with cancer. J Pain Symptom Manage 19:363-377

13. Collins JJ, Devine TD, Dick GS, Johnson EA, Kilham HA, Pinkerton CR, Stevens MM, Thaler HT, Portenoy RK (2002) The measurement of symptoms in young children with cancer: the validation of the Memorial Symptom Assessment Scale in children aged 7-12. J Pain Symptom Manage 23:10-16

14. DeWalt DA, Rothrock N, Yount S, Stone AA, PROMIS Cooperative Group (2007) Evaluation of item candidates: the PROMIS qualitative item review. Med Care 45:S12-21

15. Davison SN, Jhangri GS, Johnson JA (2006) Cross-sectional validity of a modified Edmonton symptom assessment system in dialysis patients: a simple assessment of symptom burden. Kidney Int 69:1621-1625

16. Naegeli AN, Hanlon J, Gries KS, Safikhani S, Ryden A, Patel M, Crescioni M, Vernon M (2017) Literature review to characterize the empirical basis for response scale selection in pediatric populations. J Patient Rep Outcomes 2:39

17. Arnold BF, Galiani S, Ram PK, Hubbard AE, Briceno B, Gertler PJ, Colford JM Jr (2013) Optimal recall period for caregiverreported illness in risk factor and intervention studies: a multicountry study. Am J Epidemiol 177:361-370

18. Schwartz GJ, Munoz A, Schneider MF, Mak RH, Kaskel F, Warady BA, Furth SL (2009) New equations to estimate GFR in children with CKD. J Am Soc Nephrol 20:629-637

19. Riley AW (2004) Evidence that school-age children can selfreport on their health. Ambul Pediatr 4:371-376

20. Knafl K, Deatrick J, Gallo A, Holcombe G, Bakitas M, Dixon J, Grey M (2007) The analysis and interpretation of cognitive interviews for instrument development. Res Nurs Health 30:224-234

21. Harris PA, Taylor R, Thielke R, Payne J, Gonzalez N, Conde JG (2009) Research electronic data capture (REDCap)-a metadatadriven methodology and workflow process for providing translational research informatics support. J Biomed Inform 42:377-381

22. Saban JA, Zappitelli M, Samuel SM, Sood MM, Alexander RT, Arora S, Erickson RL, Kroeker K, Manns BJ, Dart AB (2016) Perceptions of pediatric nephrologists regarding timing of dialysis initiation in children in Canada. Can J Kidney Health Dis 3:31

23. Nesrallah GE, Mustafa RA, Clark WF, Bass A, Barnieh L, Hemmelgarn BR, Klarenbach S, Quinn RR, Hiremath S, Ravani P, Sood MM, Moist LM, Canadian Society of Nephrology (2014) Canadian Society of Nephrology 2014 clinical practice guideline for timing the initiation of chronic dialysis. CMAJ 186:112-117
24. Kwekkeboom KL, Wieben A, Stevens J, Tostrud L, Montgomery K (2020) Guideline-recommended symptom management strategies that cross over two or more cancer symptoms. Oncol Nurs Forum 47:498-511

25. Davison SN, Jhangri GS, Johnson JA (2006) Longitudinal validation of a modified Edmonton symptom assessment system (ESAS) in haemodialysis patients. Nephrol Dial Transplant 21:3189-3195

26. Flythe JE, Powell JD, Poulton CJ, Westreich KD, Handler L, Reeve BB, Carey TS (2015) Patient-reported outcome instruments for physical symptoms among patients receiving maintenance dialysis: a systematic review. Am J Kidney Dis 66:1033-1046

27. Kerklaan J, Hannan E, Baumgart A, Manera KE, Ju A, McCulloch M, Admani B, Dominello A, Esezobor C, Foster B, Hamilton A, Jankauskiene A, Johnson RJ, Liu I, Marks SD, Neu A, Schaefer F, Sutton S, Wolfenden S, Craig JC, Groothoff J, Howell M, Tong A (2020) Patient- and parent proxy-reported outcome measures for life participation in children with chronic kidney disease: a systematic review. Nephrol Dial Transplant 35:1924-1937

28. Ju A, Josephson MA, Butt Z, Jowsey-Gregoire S, Tan J, Taylor Q, Fowler K, Dobbels F, Caskey F, Jha V, Locke J, Knoll G, Ahn C, Hanson CS, Sautenet B, Manera K, Craig JC, Howell M, Rutherford C, Tong A, Harden P, Hawley C, Holdaas H, Israni A, Jesse M, Kane B, Kanellis J, Kiberd B, Kim J, Larsen C, Leichtman A, Lentine K, Malone A, Mannon R, Oberbauer R, Patzer R, Peipert JD, Phan HA, Poggio E, Reed R, Scandling J, Tang I, Watson C, Contrares D, Contreras P, Cross D, Juodvalkis E, Koide D, Koide J, Kozarewicz A, Kozarewicz L, Kozarewicz R, Koritala A, Lisiecki E, Lipuma C, Lyman M, Mueller R, Mueller G, Noble L, Nolan N, Nolan S, Thomas J, Urbancyzk L, Zerante J, Zerante S, SONG-Tx Life Participation Workshop Investigators; Health professionals (*includes 2 patients from the SONG-Tx Graft Health Expert Working Group) Patients and family members (2019) Establishing a core outcome measure for life participation: a standardized outcomes in nephrology-kidney transplantation consensus workshop report. Transplantation 103:1199-1205

Publisher's note Springer Nature remains neutral with regard to jurisdictional claims in published maps and institutional affiliations. 